GENERAL VIOLENCE

\title{
Deaths from violence in North Carolina, 2004: how deaths differ in females and males
}

\author{
C Sanford, S W Marshall, S L Martin, T Coyne-Beasley, A E Waller, P J Cook, T Norwood, \\ Z Demissie
}

Injury Prevention 2006;12(Suppl II):ii10-ii16. doi: 10.1136/ip.2006.012617

See end of article for authors' affiliations

.....................

Correspondence to: Mrs C (Kay) Sanford Director, NC Violent Death Reporting System, Injury and Violence Prevention Branch, NC Division of Public Health, 1915 Mail Service Center, Raleigh NC 27699-1915, USA; kay.sanford@ncmail.net

Accepted 3 August 2006
Objective: To identify gender differences in violent deaths in terms of incidence, circumstances, and methods of death.

Design: Analysis of surveillance data.

Setting: North Carolina, a state of 8.6 million residents on the eastern seaboard of the US.

Subjects: 1674 North Carolina residents who died from violence in the state during 2004.

Methods: Information on violent deaths was collected by the North Carolina Violent Death Reporting System using data from death certificates, medical examiner reports, and law enforcement agency incidence reports.

Results: Suicide and homicide rates were lower for females than males. For suicides, females were more likely than males to have a diagnosis of depression (55\% v 36\%), a current mental health problem $(66 \% \mathrm{v}$ $42 \%)$, or a history of suicide attempts (25\% v 13\%). Firearms were the sole method of suicide in $65 \%$ of males and $42 \%$ of females. Poisonings were more common in female than male suicides (37\% v12\%). Male and female homicide victims were most likely to die from a handgun or a sharp instrument. Fifty seven percent of female homicides involved intimate partner violence, compared with 13\% of male homicides. Among female homicides involving intimate partner violence, 78\% occurred in the woman's home. White females had a higher rate of suicide than African-American females, but African-American females had a higher rate of homicide than white females.

Conclusions: The incidence, circumstances, and methods of fatal violence differ greatly between females and males. These differences should be taken into account in the development of violence prevention efforts.
$\mathrm{D}$ eaths from violence exact a high burden of suffering worldwide. ${ }^{1}$ Suicides and homicides are at epidemic proportions in the US. ${ }^{2}$ Almost 51000 US residents die every year from violence. ${ }^{3}$ The most common manner of violent death for both females and males is suicide, followed by homicide. ${ }^{4}$ In the US, suicide and homicide rates have been consistently lower among females than males. ${ }^{45}$

Research has started to compare female and male suicides in terms of a variety of factors, including the demographic characteristics, and the methods that they used to kill themselves (firearm, poisoning, etc). This research has generally found racial differences in suicides. Suicide is more common among whites than blacks for both females and males. ${ }^{4}$ Age is also associated with suicide. Females and males are more likely to commit suicide between the ages of 25 and 44, and males are more likely to commit suicide after age $65 .{ }^{6}$ Although the majority of suicides are committed using firearms, females are more likely than males to use other types of suicide methods, especially poisoning. ${ }^{6}$ Females tend to attempt suicide more frequently than males; however males' attempts are more likely to be fatal. ${ }^{7}$

Likewise, extensive research has examined various aspects of female and male homicides. Most research has found racial differences in homicide rates of both females and males. Blacks are more likely than whites to be homicide victims. ${ }^{4}$ In addition, homicide rates vary by age. Males aged 20-24 years and females aged 25-34 are at the highest risk for homicide. ${ }^{3}$ Firearms are the most commonly used method of homicide in the US, accounting for $56 \%$ of all homicides in $2001 .^{3}$ Firearm inflicted homicides are more common among males than females. ${ }^{589}$ In the majority of female and male homicides, the suspect/perpetrator is known to the victim. ${ }^{10}$ However, female homicides are more likely than male homicides to be committed by an intimate partner or family member, whereas male homicides are more likely than female homicides to be committed by a stranger or an

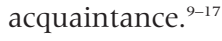

Although past research suggests that the mechanisms and circumstances of deaths from violence in females and males differ, few details have been available concerning these differences. The findings from the first year of data from the North Carolina Violent Death Reporting System (NC-VDRS) provide an opportunity to begin assessing traditional and novel data on circumstances concerning deaths from violence gathered from multiple sources. This timely information will be helpful to public health practitioners and others in their efforts to design and implement more effective violence prevention programs.

\section{METHODS}

The National Violent Death Reporting System (NVDRS) is a new US database of incidents where "the intentional use of physical force or power against oneself, another person, or against a group or community" resulted in at least one death of the people involved in the incident. The system contains detailed standardized information on victims and suspects, characteristics of the relationship(s) between victim(s) and

Abbreviations: ICD-10, International Classification of Diseases, 10th revision; NC-VDRS, North Carolina Violent Death Reporting System; NVDRS, National Violent Death Reporting System; OCME, Office of the Chief Medical Examiner. 


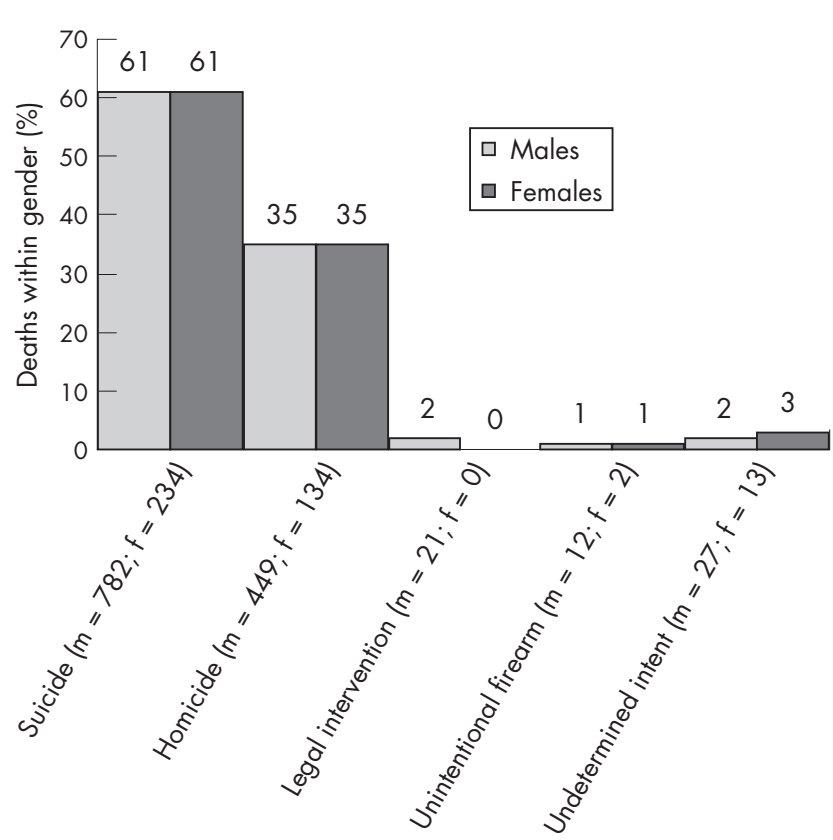

Figure 1 Manner of death by sex. North Carolina residents, 2004.

suspect(s), descriptions of the mechanism/method that resulted in the death, and detailed information on the circumstances that led to, or occurred during, the death. This information is gathered by trained abstracters from multiple sources, including death certificates, medical examiner records, law enforcement reports and crime laboratories. The purpose and data collection methods used in the NVDRS are fully described elsewhere. ${ }^{18}$

The North Carolina Violent Death Reporting System (NCVDRS) began collecting data on 1 January 2004. Eligible incidents are identified by matching death certificates and medical examiner information using manner of death and NVDRS-selected International Classification of Disease, 10th revision (ICD-10) codes. ${ }^{18}$

The data analyzed in this paper included all NVDRSeligible deaths that occurred in state residents who died in North Carolina during the 2004 calendar year. Age and race specific mortality rates were calculated per 100000 population with $95 \%$ confidence intervals. Mortality rates were not computed when the number of deaths was less than 15. The NC-VDRS is approved by the Public Health IRB at the University of North Carolina at Chapel Hill and the NC Division of Public Health.

\section{RESULTS}

There were a total of 1730 deaths from violence in North Carolina in 2004. Most of these deaths were North Carolina residents (96\%) who died in-state. This paper refers to these 383 female deaths (23\%) and 1291 male deaths (77\%). Data were also examined on the 330 suspects on whom information was available who were involved in these 1674 deaths, including suspects who were not state residents.

The overall mortality rates per 100000 population from violence by gender were much lower in females $(8.8 ; 95 \% \mathrm{CI}$ 7.9 to 9.7 ) than in males $(30.7 ; 95 \%$ CI 29.0 to 32.4 ). For suicide and homicide, there were at least three times as many violent deaths among males compared to females. There were 234 female suicides and 782 male suicides. There were 134 female homicides and 449 male homicides. In contrast to the mortality patterns between females and males, the withingender percentage of mortality for suicides and homicides was identical: $61 \%$ of both females and males died by suicide and $35 \%$ of both females and males were victims of homicides (fig 1).

Comparable gender patterns for deaths from suicide and homicide were not observed for deaths from unintentional firearms ( 2 females $v 12$ males), legal intervention ( 0 females $v 21$ males), and undetermined intent (13 females $v 27$ males). Because the number of these deaths was only $4.5 \%$ of the total, the remainder of the results focuses only on suicide and homicide and considers them separately.

\section{Suicide}

The NC suicide rate per 100000 population in females in $2004(5.4 ; 95 \%$ CI 4.7 to 6.1$)$ was less than half the suicide rate for males $(18.6$; 95\% CI 17.3 to 19.9). Suicides were largely concentrated in whites (table 1). The distribution by race was similar for female and male suicides (approximately $90 \%$ white). However, the white to African American suicide rates were 3.3 times as high in females (6.6 per 100000 population $v 2.0$ ) and 2.4 times as high in males (21.8 per 100000 population $v 8.9)$.

The age profiles of NC suicides varied by gender in 2004 (table 1). The highest age specific suicide rate per 100000 population was observed for females between ages 45 to 54 (9.6; $95 \%$ CI 7.1 to 12.1$)$. The highest suicides rates for males occurred between ages 35 to 44 (29.0; $95 \%$ CI 24.8 to 33.1$)$ and in the age groups of 75 to $84(38.2 ; 95 \%$ CI 27.9 to 48.5$)$ and 85 and older $(55.8 ; 95 \%$ CI 30.7 to 80.9$)$.

Suicides were most often initiated in a house or apartment in both females $(85 \%)$ and males $(83 \%)$.

Firearms were the most common method of suicide overall $(60 \%)$ and for both males (65\%) and females (42\%) (fig 2). The majority of firearms used were handguns (66\%). In contrast to males, the method of suicide among females was almost equally divided between firearms $(42 \%)$ and poisons (37\%) (fig 2), accounting for $79 \%$ of female suicides. Hanging, strangulation, and asphyxiation were the third most common method of suicide in females and the second most common method in males.

Over one half of female $(62 \%)$ and male suicide victims $(56 \%)$ were reported by a friend or family member as having a depressed mood immediately prior to death (table 2 ). When a medical history was recorded, $66 \%$ of the females who committed suicide were reported as having a current mental health problem-most were a diagnosis of depression (55\%). This proportion of depression in females was much higher than was reported for male suicides $(36 \%)$. Female suicide victims (58\%) were nearly twice as likely as males $(33 \%)$ to have been currently receiving mental health services, defined as having a current prescription for a psychiatric medication, or seeing a mental health professional within the two months prior to suicide. One quarter of females who committed suicide $(n=55)$, in contrast to one eighth of males $(n=90)$, had a history of at least one previous suicide attempt. Less than one quarter of the females and males disclosed their intent to commit suicide and less than a one third left a suicide note.

New types of information in the NVDRS from medical examiners and law enforcement appear to shed light on the circumstances associated with suicide. One example is a history of having had a crisis or an acute precipitating event that appeared to have contributed to the suicide. These are defined in the NVDRS as physical health, intimate partner, other relationship, job, school, financial, or legal problems that occurred within two weeks of the death or were scheduled to occur within two weeks after the victim's deaths.

A crisis was reported to have occurred in $22 \%$ of the 234 females and $29 \%$ of the 782 males who committed suicide. 


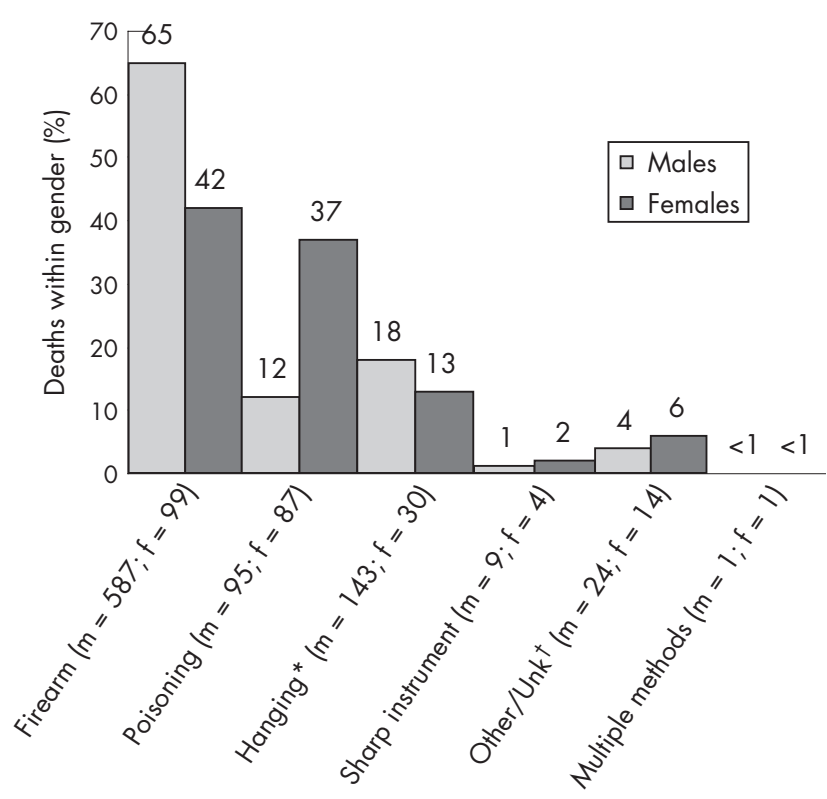

Figure 2 Method of death by sex for suicides. North Carolina residents, 2004. *Hanging, strangulation, asphyxiation; †Drowning, fire/burn, fall, etc.

For suicide victims with a history of intimate partner violence (48 females and 217 males), over half of the females (57\%) and males $(54 \%)$ were reported to have had a crisis. Fifty two males $(7.3 \%)$ who committed suicide were reported to have been a perpetrator of intimate partner violence; of these, $78 \%$ had a crisis. Only two female suicides were perpetrators of intimate partner violence $(0.9 \%)$.

\section{Homicide}

The homicide rate per 100000 population in females in 2004 was 3.1 (95\% CI 2.6 to 3.6). As with suicide, this is less than one third the homicide rate for males $(10.7 ; 95 \%$ CI 9.7 to 11.7). There is greater interracial variation in homicide rates (table 3 ) than observed in suicide rates (table 1) for males. The homicide rate per 100000 population in African American females $(5.2 ; 95 \%$ CI 3.8 to 6.6 ) was over twice that for white females $(2.4 ; 95 \%$ CI 1.9 to 2.9$)$, whereas the homicide rate per 100000 population in African American males $(27.7 ; 95 \%$ CI 24.3 to 31.2$)$ was almost five times the rate in white males $(5.6 ; 95 \%$ CI 4.8 to 6.5$)$.

The highest rate of homicides per 100000 population in females $(5.3 ; 95 \%$ CI 3.35 to 7.0$)$ occurred at an older age (35-44 years) than the highest rate $(27.2 ; 95 \%$ CI 21.4 to 32.9) in males (ages 20-24) (table 3).

Firearms and sharp instruments were the predominant methods of homicide among females and males (fig 3). Patterns, however, differed by sex. Firearms resulted in $71 \%$ of the homicides in males $(n=318)$, in contrast to $48 \%$ in females $(n=64)$. The handgun was the most common type of firearm used in male $(66 \%)$ and female $(61 \%)$ homicides. Sharp instruments were used more often in female homicides $(20 \%)$ than in male homicides (15\%). More females (11\%) than males $(2 \%)$ were killed by hanging, strangulation, and suffocation.

For those homicide cases in which the number of suspects could be determined ( $70 \%$ in females and $61 \%$ in males), the relationship of the victim to the suspect (table 4 ) differed by sex. When known, the suspect in female homicides was more likely to be a spouse, ex-spouse, boyfriend/girlfriend, or former boyfriend/girlfriend $(\mathrm{n}=38,28 \%)$, than in male homicides $(\mathrm{n}=19,4 \%)$. A stranger was reported only once as the suspect in all female homicides $(0.7 \%)$ in contrast to the suspect being reported as a stranger $(\mathrm{n}=14)$ in male homicides $(3 \%)$. Rape or sexual assault $(n=6)$ was reported for $6 \%$ of the females homicides and none of the male homicides.

Argument, abuse, or conflict were the most common precipitating factors of female $(\mathrm{n}=79,76 \%)$ and male $(\mathrm{n}=193,65 \%)$ homicides (table 4). The frequency of arguments that resulted in death differed by gender. Intimate partner violence was listed as a circumstance in 98 NC homicides in 2004 and was the leading cause of female homicide $(57 \%)$, in contrast to male homicide $(13 \%)$. The decedent was female in $60 \%$ of homicides that involved intimate partner violence. Most $(78 \%)$ of the fatalities in females from intimate partner violence occurred in the woman's home.

\section{DISCUSSION}

In 2004, suicides were the leading cause of death from violence in North Carolina and the US. Consistent with

\begin{tabular}{|c|c|c|c|c|c|c|}
\hline & \multicolumn{3}{|c|}{ Females } & \multicolumn{3}{|c|}{ Males } \\
\hline & $\mathbf{n}$ & $\%$ & Rate $^{*}(95 \% \mathrm{Cl})$ & $\mathbf{n}$ & $\%$ & $\operatorname{Rate}^{*}(95 \% \mathrm{Cl})$ \\
\hline \multicolumn{7}{|l|}{ Race } \\
\hline White & 210 & 89.7 & $6.6(5.7$ to 7.4$)$ & 690 & 88.2 & $21.8(20.1$ to 23.4$)$ \\
\hline Black & 20 & 8.6 & $2.0(1.1$ to 2.9$)$ & 79 & 10.1 & 8.9 (6.9 to 10.8$)$ \\
\hline Other & 4 & 1.7 & - & 13 & 1.7 & - \\
\hline \multicolumn{7}{|c|}{ Age (years) } \\
\hline$<1$ & 0 & 0.0 & - & 0 & 0.0 & - \\
\hline $1-4$ & 0 & 0.0 & - & 0 & 0.0 & - \\
\hline $5-9$ & 0 & 0.0 & - & 0 & 0.0 & - \\
\hline $10-14$ & 1 & 0.4 & - & 8 & 1.0 & - \\
\hline $15-19$ & 7 & 3.0 & - & 39 & 5.0 & $13.3(9.1$ to 17.4$)$ \\
\hline $20-24$ & 13 & 5.6 & $4.6(2.1$ to 7.0$)$ & 69 & 8.8 & 21.8 (16.6 to 26.9 ) \\
\hline $25-34$ & 30 & 12.8 & $5.0(3.2$ to 6.7$)$ & 149 & 19.1 & $23.4(19.6$ to 27.1$)$ \\
\hline $35-44$ & 57 & 24.4 & $8.8(6.5$ to 11.1$)$ & 186 & 23.8 & $29.0(24.8$ to 33.1$)$ \\
\hline $45-54$ & 58 & 24.8 & $9.6(7.1$ to 12.1$)$ & 116 & 14.8 & 20.3 (16.6 to 24$)$ \\
\hline $55-64$ & 37 & 15.8 & $8.3(5.6$ to 11.0$)$ & 83 & 10.6 & 20.3 (15.9 to 24.0$)$ \\
\hline $65-74$ & 20 & 8.5 & 6.5 (3.7 to 9.4$)$ & 59 & 7.5 & 23.7 (17.7 to 29.8$)$ \\
\hline $75-84$ & 8 & 3.4 & - & 53 & 6.9 & $38.2(27.9$ to 48.5$)$ \\
\hline$\geqslant 85$ & 3 & 1.3 & - & 19 & 2.4 & 55.8 (30.7 to 80.9$)$ \\
\hline
\end{tabular}


Table 2 Suicide event characteristics, North Carolina residents, 2004*

\begin{tabular}{|c|c|c|c|c|}
\hline & \multicolumn{2}{|c|}{ Females } & \multicolumn{2}{|c|}{ Males } \\
\hline & n & $\%$ & $\mathbf{n}$ & $\%$ \\
\hline Victim had a current depressed mood & 138 & 61.6 & 401 & 56.2 \\
\hline Victim had a current mental health problem† & 146 & 66.4 & 295 & 42.1 \\
\hline Diagnosis of depression & 121 & 55.0 & 252 & 36.0 \\
\hline Diagnosis of bipolar disorder & 15 & 6.8 & 21 & 3.0 \\
\hline Victim was currently receiving mental health treatment & 130 & 58.0 & 232 & 32.5 \\
\hline Victim had a history of previous suicide attempts & 55 & 24.6 & 90 & 12.6 \\
\hline Victim left a suicide note & 65 & 29.0 & 175 & 24.5 \\
\hline Victim disclosed intent to commit suicide & 50 & 22.3 & 176 & 24.7 \\
\hline Death or suicide of family member or friend contributed to suicide & 22 & 9.8 & 36 & 5.0 \\
\hline Problem with intimate partner contributed to suicide & 48 & 21.4 & 217 & 30.4 \\
\hline Victim experienced a crisis within two weeks of the suicide & 49 & 21.9 & 207 & 29.0 \\
\hline
\end{tabular}

national data, the 2004 NC-VDRS data found that the mortality rates from suicide and homicide were consistently lower in females than in males. For both males and females, suicide rates were about twice as high as homicide rates (rate ratios of 1.7 in both males and females), and the proportion of suicides $(61 \%)$ and homicide $(35 \%)$ to all deaths from violence and unintentional firearms was the same for NC males and females. These data are supported by other larger and more long term studies on homicides and suicides, and suggest that these new insights may be immediately useful public health information.

NC-VDRS data indicate that there are several critical factors specific to death from violence in females that are not as frequently reported in males. Females who committed suicide in NC were more likely than males to have a medical diagnosis of depression and females were also more likely than males to have a history of suicide attempts. Intimate partner violence was the dominant cause of female homicide, whereas a male homicide more often resulted from other types of arguments or conflict. The suspect in homicides was more likely to have been a spouse/ex-spouse/intimate partner or former intimate partner of females than males. Among NC African American females, the homicide rate exceeded the suicide rate, whereas the opposite was true for white females.

Despite decades of research into suicide, many key questions remain unanswered. The NC-VDRS clearly demonstrated that women commit suicide by poison more often than men. However, many more years of information on circumstances will need to be collected if we are to understand why females select poisons over firearms, and what are the inciting events. We need to know how we can capitalize on the advantages afforded by the facts that females are more likely than males to have seen a professional for depression or have had a prior suicide attempt, and that females are more likely than males to survive a suicide attempt. Research suggests that firearms have a higher case fatality rate than poisonings. ${ }^{19}$ Therefore, in terms of developing and implementing intervention strategies, the difference in the choice of suicide method may be the most profound difference between females and males since it the main reason that females are more likely than males to survive a suicide attempt.

NC-VDRS data strongly suggest that more resources should be devoted to the primary prevention of suicide, and support the Institute of Medicine's recommendations on reducing suicides. ${ }^{20}$ This includes funding more gatekeeper training, currently underway in North Carolina; the piloting of programs for coping and resiliency training as part of the curriculum for school aged children and continuing education for seniors; and the development and dissemination to primary care providers of tools for the recognition, screening, and referral to mental health professionals of patients with

\begin{tabular}{|c|c|c|c|c|c|c|}
\hline & \multicolumn{3}{|c|}{ Females } & \multicolumn{3}{|c|}{ Males } \\
\hline & $\mathrm{n}$ & $\%$ & Rate $^{*}(95 \% \mathrm{Cl})$ & $\mathrm{n}$ & $\%$ & $\operatorname{Rate}^{*}(95 \% \mathrm{Cl})$ \\
\hline \multicolumn{7}{|l|}{ Race } \\
\hline White & 77 & 57.6 & 2.4 (1.9 to 2.9 ) & 179 & 40.1 & $5.6(4.8$ to 6.5$)$ \\
\hline Black & 52 & 38.8 & $5.2(3.8$ to 6.6$)$ & 247 & 54.8 & 27.7 (24.3 to 31.2 ) \\
\hline Other & 5 & 3.8 & - & 23 & 5.2 & - \\
\hline \multicolumn{7}{|c|}{ Age (years) } \\
\hline$<1$ & 3 & 2.3 & - & 9 & 2.0 & - \\
\hline $1-4$ & 1 & 0.8 & - & 13 & 2.9 & - \\
\hline $5-9$ & 0 & 0.0 & - & 1 & 0.2 & - \\
\hline $10-14$ & 5 & 3.8 & - & 8 & 1.8 & - \\
\hline $15-19$ & 8 & 6.0 & - & 28 & 6.2 & 9.5 (6.0 to 13.0$)$ \\
\hline $20-24$ & 14 & 10.5 & 4.9 (2.3 to 7.5$)$ & 86 & 19.2 & $27.2(21.4$ to 32.9$)$ \\
\hline $25-34$ & 29 & 21.8 & $4.8(3.1$ to 6.5$)$ & 125 & 27.8 & 19.6 (16.2 to 23.0$)$ \\
\hline $35-44$ & 34 & 25.6 & 5.3 (3.5 to 7.0$)$ & 74 & 16.5 & 11.5 (8.9 to 14.2 ) \\
\hline $45-54$ & 13 & 9.8 & $2.2(1.0$ to 3.3$)$ & 62 & 12.8 & $10.9(8.2$ to 13.6$)$ \\
\hline $55-64$ & 9 & 6.8 & - & 27 & 6.0 & $6.6(4.1$ to 9.1$)$ \\
\hline $65-74$ & 12 & 9.0 & $3.9(1.7$ to 6.1$)$ & 6 & 1.3 & - \\
\hline $75-84$ & 3 & 2.3 & - & 9 & 2.0 & - \\
\hline$\geqslant 85$ & 2 & 1.5 & - & 1 & 0.2 & - \\
\hline
\end{tabular}




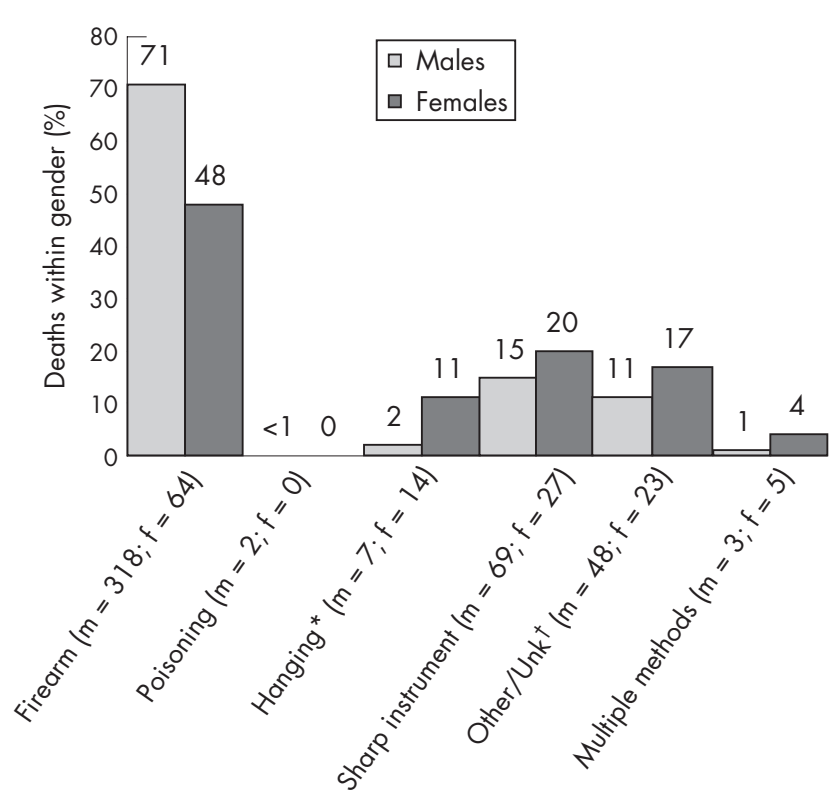

Figure 3 Method of death by sex for homicides. North Carolina residents, 2004. *Hanging, strangulation, asphyxiation; †Drowning, fire/burn, fall, etc.

acute and chronic suicide risk factors. ${ }^{20}$ Also necessary are improved availability of and access to mental health services and more effective suicide prevention counseling for youth and the elderly. Mental health services should be assessed to ensure that they are specific to the different needs of females and males, and that they are responsive to indicators of imminent crises that may lead to suicide. Although poisons were used in many suicides among females, firearms were the most common methods used in suicides among males and females. Research by others suggests that limiting access to firearms may be an important and effective strategy for reducing suicide deaths. ${ }^{719}$
Homicides in females showed some similarity to male homicides. However, NC-VDRS data and other sources, ${ }^{11-}$ $14^{17}{ }^{21-23}$ make it clear that intimate partner violence plays a leading role in many female homicides. A study of female homicides among North Carolina adolescents also revealed that female adolescents were most commonly killed by an intimate partner. ${ }^{23}$ Primary prevention of intimate partner violence should include programs to teach adolescents about healthy relationships and how to prevent dating violence. A greater awareness of intimate partner violence and its potential for homicide among the general public may be a powerful agent for long term change. Thus, the provision of frequent, timely, and accurate statistics via the national and state VDRS programs is, in itself, an intervention. For the short term acute phase of these attacks, dedicated policing teams, stronger legislation aimed at protecting females, more support for, and use of, domestic violence protective orders, and the provision of safe havens and support networks, are critical prevention initiatives that need to be supported and strengthened at the local, state, and federal level.

One of the strengths of the North Carolina death investigation system is the North Carolina Office of the Chief Medical Examiner (OCME), which oversees a statewide system of trained medical examiners who investigate all nonnatural deaths, complete most sections of the death certificate, and complete a standardized field investigation report that is reviewed by an OCME pathologist. Most deaths from violence are autopsied and are part of the data abstracted by NC-VDRS staff. Almost all North Carolina law enforcement agencies provide incident reports to the NCVDRS. This study also benefited from being associated with the NVDRS as it employs standard and consistent definitions and case-finding methodologies for all deaths from violence from multiple sources of data.

However, because the system is based on the collection of data from existing records, the completeness of the information is limited by the accuracy and depth of detail recorded by sources such as the medical examiner investigating a non-natural death and law enforcement officers completing incident reports. A specific weakness of the NC-VDRS data is

Table 4 Homicide event characteristics. North Carolina residents, 2004

\begin{tabular}{|c|c|c|c|c|}
\hline & \multicolumn{2}{|c|}{ Females } & \multicolumn{2}{|c|}{ Males } \\
\hline & $n$ & $\%$ & $n$ & $\%$ \\
\hline \multicolumn{5}{|l|}{ Relationship of victim to suspect } \\
\hline Spouse/ex-spouse & 15 & 11.2 & 3 & 0.7 \\
\hline Current/former boyfriend/girlfriend & 23 & 17.2 & 16 & 3.6 \\
\hline Parent/stepparent & 1 & 0.7 & 6 & 1.4 \\
\hline Child/stepchild & 2 & 1.5 & 15 & 3.4 \\
\hline Other family member* & 3 & 2.1 & 10 & 2.1 \\
\hline Friend & 1 & 0.7 & 14 & 3.1 \\
\hline Acquaintance & 7 & 5.2 & 58 & 12.9 \\
\hline Other person, known to victimt & 1 & 0.7 & 9 & 2.0 \\
\hline Stranger & 1 & 0.7 & 14 & 3.1 \\
\hline Law enforcement officer injured in the line of duty & 0 & 0.0 & 1 & 0.2 \\
\hline Number of suspects known, but relationship of victim to suspect unknown & 40 & 29.9 & 136 & 30.3 \\
\hline No identified suspect or suspects & 40 & 29.9 & 175 & 39.0 \\
\hline Homicide related to argument, abuse or conflictł & 79 & 75.9 & 193 & 64.5 \\
\hline Intimate partner violence & 59 & 56.7 & 39 & 13.0 \\
\hline Argument over money or property & 2 & 1.9 & 10 & 3.3 \\
\hline Other argument, abuse or conflict & 18 & 17.3 & 144 & 48.2 \\
\hline Homicide was precipitated by another crimef & 23 & 22.1 & 74 & 24.8 \\
\hline Robbery & 9 & 8.7 & 42 & 14.1 \\
\hline Rape or sexual assault & 6 & 5.8 & 0 & 0.0 \\
\hline Other crime & 6 & 4.5 & 28 & 6.4 \\
\hline Homicide was drug related $\ddagger$ & 7 & 6.7 & 49 & 16.4 \\
\hline Victim used a weapon $\ddagger$ & 2 & 1.9 & 29 & 9.7 \\
\hline
\end{tabular}




\section{Key points}

- Information from the Violent Death Reporting System is very useful in comparing violent deaths between males and females.

- Suicide and homicide rates are lower for females than males.

- Firearms are the most common method of death for male and female suicides and homicides.

- Females who commit suicide are more likely than males who commit suicide to have had mental health problems and previous suicide attempts.

- Female homicides are more likely than male homicides to involve intimate partner violence.

the high proportion of missing data on suspects, particularly in cases for which there are no known suspects. Another specific weakness is that circumstances information recorded by medical examiners amd law enforcement may be subject to underreporting, for example with regard to history of mental illness or previous attempts for suicide victims. Underreporting could occur if relatives or family members were unaware or unwilling to provide this information, or if authorities were unable or neglected to ascertain this information.

\section{CONCLUSION}

Fatal violence in females is distinct from fatal violence in men. Current prevention initiatives addressing violence in females need to be strengthened, and new gender-specific initiatives developed, if we are to successfully address violence that leads to fatalities. The primary prevention of intimate partner violence, including dating violence, and more effective mental health services, particularly when a diagnosis of depression or a suicide attempt has been made, are two pressing areas that these data suggest should be addressed. As most deaths from violence are suicides, further research should examine and develop effective therapeutic and programmatic approaches to individuals with diagnoses of depression and suicide attempts. Finally, research is needed to develop and evaluate effective, comprehensive, and evidence-based primary prevention programs for all types of violence that have the potential to result in death.

\section{ACKNOWLEDGEMENTS}

The North Carolina Violent Death Reporting System is operated by the NC Department of Health and Human Services Division of Public Health Injury and Violence Prevention Branch. It is funded by the National Center for Injury Prevention and Control at the Centers for Disease Control and Prevention, Cooperative Agreement U17CCU423098. We wish to thank the UNC Injury Prevention Research Center, the members of the NC-VDRS Data Users Advisory Board (Tamera Coyne-Beasley, Chair, Departments of Pediatrics and Internal Medicine, UNC-Chapel Hill; Steven Chalmers, Chief of Police, Durham Police Department; Megan Davies, CDC; Jeanne Givens, NC-DHHS; Peggy Goodman, Department of Emergency Medicine, East Carolina University; Jane Ann Miller, NC-DHHS; Lisa Price, North Carolinians Against Gun Violence Education Fund, Inc; Joel Rosch, Duke University; Leslie Starsoneck, Prevent Child Abuse North Carolina; Delores Steele, NC Council for Females and Domestic Violence Commission; Jennifer Tolle-Whiteside, Prevent Child Abuse North Carolina; David C Wiesner, Licensed Psychologist, Raleigh; Betty Wiser, NC-DHHS); the NC-VDRS Technical Advisory Board (Anna E Waller, Chair and Amy Ising; Department of Emergency Medicine, UNC-Chapel Hill; Patricia Barnes, North Carolina Office of the Chief Medical Examiner; Kathleen Jones-Vessey, NC State Center for Health Statistics; and Timothy
Parker, NC, State Bureau of Investigation); and the NC-VDRS Durham Community Advisory Board (Philip J Cook, Co-Chair, Duke University; Tamera Coyne-Beasley, Co-Chair, Departments of Pediatrics and Internal Medicine, UNC-Chapel Hill; John Byrd, Durham Police Department; Annette Carrington, Durham County Health Department; Robert Faggart, Durham Police Department; Phillip Graham, RTI International; Brian Letourneau, Director, Durham County Health Department; Captain Steven Mihaich, Commander of Special Operations Division, Durham Police Department; Beth Moracco, Pacific Institute for Research and Evaluation; Marcia Owen, Religious Coalition for a Nonviolent Durham; Rebecca Reyes, Latino Health Project Coordinator, Duke University; Mike Smith, Durham County Emergency Medical Services; Kevin Strom, RTI International), and former NC-VDRS staff members Eleanor Howell and Krista Ragan.

\section{Authors' affiliations}

C Sanford, T Norwood, Injury and Violence Prevention Branch, Division of Public Health, NC Department Health and Human Services, Raleigh, NC, USA

S W Marshall, Z Demissie, Department of Epidemiology, University of North Carolina, Chapel Hill, NC, USA

S W Marshall, S L Martin, T Coyne-Beasley, Injury Prevention Research Center, University of North Carolina, Chapel Hill, NC, USA

S L Martin, Department of Maternal and Child Heath, University of North Carolina, Chapel Hill, NC, USA

T Coyne-Beasley, Department of Pediatrics, University of North Carolina, Chapel Hill, NC, USA

A E Waller, Department of Emergency Medicine, University of North Carolina, Chapel Hill, NC, USA

P J Cook, Terry Sanford Institute of Public Policy, Duke University, Durham, NC, USA

This work was supported by the Centers for Disease Control and Prevention (CDC), National Violent Death Reporting System Grant No \#U17/CCU423098.

Competing interests: none.

\section{REFERENCES}

1 In: Krug E, Dahlburg LL, Mercy JA, (eds), et al. World report on violence and health. Geneva: World Health Organization, 2002.

2 Vyrostek SB, Annest JL, Ryan GW. Surveillance for fatal and nonfatal injuries - United States, 2001. MMWR Surv Summ 2004;53:1-57.

3 Centers for Disease Control and Prevention, National Centers for Injury Prevention and Control. Web-based Injury Statistics Query and Reporting System (WISQARS). Available at http://www.cdc.gov/ncipc/wisqars (accessed November 2005)

4 Centers for Disease Control and Prevention. Trends in rates of homicideUnited States, 1985-1994. MMWR Morb Mortal Wkly Rep 1996;45:460-4

5 Schmid D. State Center for Health Statistics Studies No 140. Suicide in North Carolina: Deaths, Hospitalizations and Youth Survey Results, Raleigh NC:Department of Health and Human Services, 2004.

6 Anderson RN, Minino AM, Fingerhut LA, et al. Deaths: injuries, 2001. Natl Vital Stat Rep 2004;52:1-86.

7 NC Division of Public Health. Saving tomorrows today, North Carolina's plan to prevent youth suicide. Raleigh, NC: Department of Health and Human Services, 2004

8 Fingerhut LA. Firearm mortality among children, youth, and young adults 134 years of age, trends and current status: United States, 1985-90. Advance data from vital and health statistics of the Centers of Disease Control and Prevention 1993;231:1-20.

9 National Institute of Justice. A study of homicide in eight U.S. cities: an NIJ intramural ressearch project, NCJ 167263. Washington DC: National Institute of Justice Research in Brief, 1997.

10 Kellerman AL, Mercy JA. Men, females, and murder: Gender-specific differences in rates of fatal violence and victimization. J Trauma 1992;33:1-5.

11 Arbuckle J, Olson L, Howard M, et al. Safe at home? Domestic violence and other homicides among females in New Mexico. Annals Emerg Med 1996;27:210-15.

12 Greenfield LA, Rand MR, Craven D, et al. Violence by intimates: an analysis of data on crimes by current or former spouses, boyfriends and girlfriends. Bureau of Justice Statistics Handbook. Washington DC: US Department of Justice, Bureau of Justice Statistics, Office of Justice Programs, 1998.

13 Mercy JA, Saltzman LE. Fatal violence among spouses in the United States, 1976-85. Am J Public Health 1989;79:595-9.

14 Moracco KE, Runyan CW, Butts JD. Femicide in North Carolina, 1991-1993: a statewide study of patterns and precursors. J Hom Studies 1998;2:422-46.

15 Parsons LH, Harper MA. Violent maternal deaths in North Carolina. Obstet Gynecol 1999;94:990-3. 
16 Paulozzi L, Saltzman LE, Thompson MP, et al. Surveillance for homicide among intimate parters-United States, 1981-1998. MMWR CDC Surveill Summ 2001;50:1-15

17 Rennison CM, Welchans S. Intimate partner violence. NCJ 178247.

Washington, DC: US Department of Justice, 2000.

18 Paulozzi L, Mercy J, Frazier L, et al. CDC's National Violent Death Reporting System: background and methodology. Inj Prev 2004;10:47-52.

19 Wadman MC, Muelleman RL, Coto JA, et al. The pyramid of injury: using $\mathrm{E}$-codes to accurately describe the burden of injury. Ann Emerg Med 2003;42:468-78.
20 Goldsmith SK, Pellmar TC, Kleinman AM, et al. Reducing suicide: a national imperative. Committee on Pathophysiology Prevention of Adolescent \& Adult Suicide, Board on Neuroscience and Behavioral Health. Washington DC: Institute of Medicine, National Academy of Sciences, 2002.

21 Bailey JE, Kellerman AL, Somes GW, et al. Risk factors for violent death of females in the home. Arch Intern Med 1997; 157:777-82.

22 Browne A. When battered females kill. New York NY: Free Press, 1987.

23 Coyne-Beasley T, Morraco E, Casteel M. Adolescent femicide: a populationbased study. Arch Pediatr Adolesc Med 2003;156:355-60. 